ТЯЖЕЛОЕ ТЕЧЕНИЕ НЕОНАТАЛЬНОГО САХАРНОГО ДИАБЕТА (СИНДРОМА УОЛКОТТА-РАЛЛИСОНА), ОБУСЛОВЛЕННОГО НОНСЕНС-МУТАЦИЕЙ В ПЕРВОМ ЭКЗОНЕ ГЕНА EIF2AK3

( Д.Н. Губаева' ${ }^{1}$ Д.Н. Лаптев ${ }^{1}$, А.Н. Тюльпаков ${ }^{1}$, Л.М. Петрова²

'ФГБУ Национальный медицинский исследовательский центр эндокринологии Минздрава России, Москва ²ОГБУЗ Белгородская детская областная больница, Белгород

Синдром Уолкотта-Раллисона является редким аутосомно-рецессивным заболеванием, характеризующимся неонатальным сахарным диабетом в сочетании с остеодисплазией и печеночной недостаточностью. Данное заболевание является наиболее частой причиной неонатального сахарного диабета у детей, родившихся от близкородственных браков. Синдром Уолкотта-Раллисона ассоциирован с мутациями в гене EIF2AK3, кодирующем трансмембранный белок PERK (pancreatic endoplasmic reticulum kinase - панкреатическая киназа эндоплазматического ретикулума), подавляющий синтез белков в случае нарушения фолдинга в эндоплазматическом ретикулуме. Помимо основных симптомов, у пациентов возможно развитие полиорганной патологии в виде острой печеночно-почечной недостаточности, низкорослости, экзокринной недостаточности поджелудочной железы, неврологических нарушений, гипотиреоза, анемии, нейтропении, рецидивирующей гипогликемии. Заболевание характеризуется высокой летальностью, более 50\% пациентов погибают в результате фульминантной печеночной недостаточности. Информированность о синдроме Уолкотта-Раллисона крайне низка в связи с редкостью его выявления, однако, учитывая тяжесть заболевания и неблагоприятный прогноз, пациентам с данным синдромом требуется своевременная диагностика и организованная работа слаженной команды специалистов.

КЛЮЧЕВЫЕ СЛОВА: синдром Уолкотта-Раллисона; неонатальный сахарный диабет; EIF2AK3; РЕRК; клинический случай

\title{
SEVERE WOLCOTT-RALLISON SYNDROME DUE TO A NONSENSE MUTATION IN THE FIRST EXON EIF2AK3
}

(c) Diliara N. Gubaeva' ${ }^{1}$ Dmitry N. Laptev ${ }^{1}$, Anatoly N. Tiulpakov' ${ }^{1}$ Lidia M. Petrova²

'Endocrinology Research Centre, Moscow, Russia

${ }^{2}$ Belgorod children's hospital, Belgorog, Russia

Wolcott-Rallison syndrome is a rare autosomal recessive disease characterized by neonatal diabetes mellitus in combination with osteodysplasia and liver failure. This disease is the most common cause of neonatal diabetes mellitus in consanguineous families. Wolcott-Rallison syndrome is associated with mutations in the EIF2AK3, the gene encoding a transmembrane enzyme PERK (pancreatic endoplasmic reticulum kinase) which inhibits the synthesis of proteins in the event of misfolding in the endoplasmic reticulum. In addition to the core symptoms patients may develop multisystemic clinical manifestation including acute renal and liver failure, short stature, exocrine pancreatic insufficiency, neuro-motor deficit, hypothyroidism, anemia, neutropenia, recurrent hypoglycemia. The disease is characterized by high mortality, more than $50 \%$ of patients die from fulminant liver failure. The awareness of Wolcott-Rallison syndrome is extremely low due to the rarity of detection, however in view of the severity of the disease and the unfavorable prognosis patients with this syndrome require timely diagnosis and care of well-organized team of specialists.

KEYWORDS: Wolcott-Rallison syndrome; neonatal diabetes mellitus; EIF2AK3; PERK; case report

\section{АКТУАЛЬНОСТЬ}

Синдром Уолкотта-Раллисона (СУР) назван в честь докторов Уолкотта и Раллисона, которые в 1972 г. впервые описали трех сибсов с неонатальным сахарным диабетом (СД) и костной дисплазией [1]. Клинически СУР проявляется перманентным неонатальным СД (ПНСД) или СД с ранним началом в сочетании с множественной эпифизарной дисплазией и другими симптомами, наиболее опасным из которых является рецидивирующая острая печеночная недостаточность. Вышеописанный синдром является наиболее частой причиной неонатального СД у детей, родившихся от близкородственных браков [2]. Частота встречаемости СУР в популяции неизвестна ввиду малого количества пациентов с данной патологией, предполагаемая распространенность составляет 1 на 215000 новорожденных [3]. Вероятно, низкая распространенность СУР объясняется не только редкостью самого заболевания, но и ранней смертью детей до установки истинного диагноза. Наибольшее количество пациентов с СУР зарегистрировано в странах среднего востока (Саудовская Аравия, Объединенные Арабские Эмираты и др.). В странах Америки и Европы описания пациентов единичны [4-6]. В русскоязычной литературе также имеется описание клинического случая пациента с СУР [7]. 


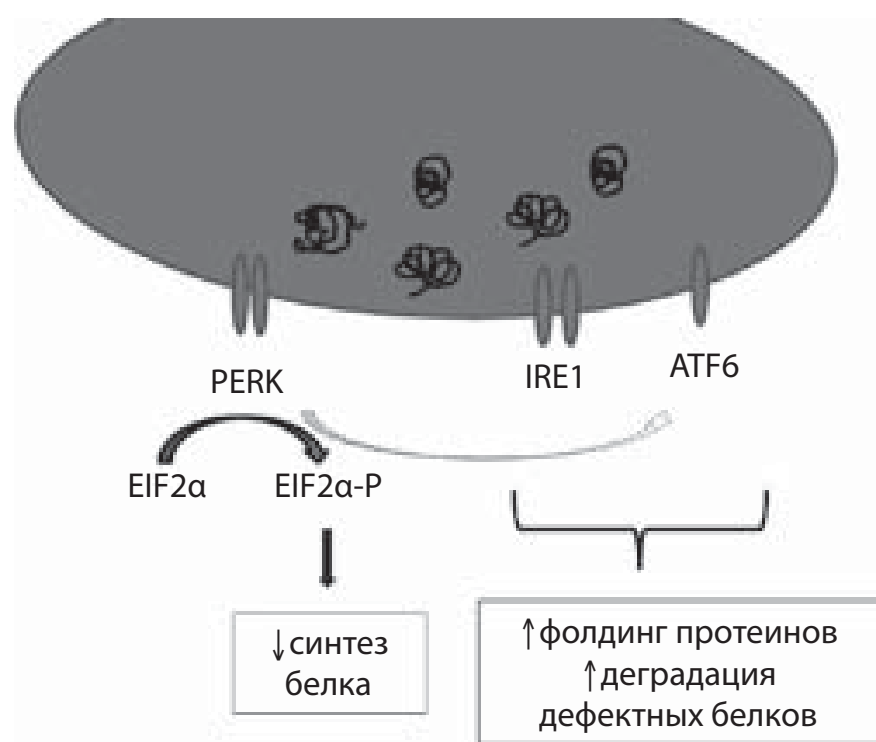

Рис. 1. Схематическое изображение защитных процессов в ответ на «стресс ЭР».

В норме в ЭР происходят синтез и фолдинг белков. В случае «стресса ЭР» и накопления неправильно сформированных протеинов активируются защитные механизмы, в которых главную роль выполняют трансмембранные белки PERK, IRE1 и ATF6. PERK приводит к фосфорилированию EIF2a, что, в свою очередь, индуцирует снижение синтеза белковых молекул, снижая нагрузку на ЭР. Также РЕRК отвечает за регуляцию ATF6. Активация трансмембранных протеинов IRE1 и ATF6 стимулирует деградацию дефектных белков и синтез шаперонов и других молекул, обеспечивающих правильное пространственное расположение молекулы белка. Дефектные белки выводятся из ЭР и подвергаются уничтожению в цитозоле.

СУР - это редкое аутосомно-рецессивное заболевание, вызванное мутациями в гене EIF2AK3. Данный ген кодирует а-киназу-3 эукариотического фактора инициации трансляции 2, также известную как PKR-подобная киназа эндоплазматического ретикулума (PERK). B основе патогенеза заболевания лежит нарушение функционирования эндоплазматического ретикулума (ЭР), одними из важнейших функций которого являются синтез белков и обеспечение их созревания. Внутри ЭР происходит фолдинг - формирование правильной трехмерной (третичной и четвертичной) структуры белков. Однако ввиду ряда факторов (например, в случае необходимости синтеза большого количества белковых продуктов) возможно развитие «стресса ЭР» - перегрузки аппарата, обеспечивающего созревание белков, что может привести к гибели клетки. В случае «стресса ЭР» и накопления в ЭР неправильно сформированных протеинов активируются трансмембранные белки PERK, IRE1 и ATF6. Для защиты клетки от критической нагрузки PERK подавляет трансляцию и синтез белка путем фосфорилирования а-субъединицы эукариотического фактора инициации трансляции 2 (EIF2a) (рис. 1). Нарушение функционирования трансмембранного белка PERK приводит к снижению устойчивости клетки к «стрессу ЭР» [8].

Обязательным компонентом синдрома, описанным у всех пациентов с СУР, является инсулинопотребный ПНСД, который обычно манифестирует в возрасте до 6 мес с кетоацидозом [9], однако в литературе описаны случаи более поздней манифестации СД. Сахарный диабет в составе описанного синдрома не носит аутоиммунного характера. Соответственно, у пациентов с СУР не выявляется повышение уровня аутоантител к остров- ковым клеткам поджелудочной железы (ICA), глутаматдекарбоксилазе (GAD) и тирозинфосфатазе (IA2) [4].

Более чем у половины пациентов развиваются скелетные аномалии в виде множественной эпифизарной дисплазии с поражением преимущественно длинных трубчатых костей, позвоночника и тазовых костей. Поражение печени, спровоцированное вирусной инфекцией, развивается у большинства пациентов (до 85,7\%), проявляется рецидивирующими эпизодами неинфекционного и неаутоиммунного гепатита, желтухой, гепатомегалией, повышением уровней трансаминаз, острой печеночной недостаточностью и, как правило, осложняется гипогликемией и полиорганной недостаточностью $[4,5,10]$. При этом острая печеночная недостаточность является причиной смерти более чем у 50\% пациентов с СУР. Помимо основных симптомов, у пациентов возможно развитие полиорганной патологии в виде нарушения функции почек, нервной и кроветворных систем, низкорослости, экзокринной недостаточности поджелудочной железы и гипотиреоза.

\section{ОПИСАНИЕ СЛУЧАЯ}

Ребенок от четвертой беременности (IIId на рис. 2); на 30-й неделе беременности у матери выявлен токсоплазмоз (получала антибиотикотерапию). Родители являются родственниками пятого порядка, здоровы. Девочка родилась в срок с нормальным весом (3610 г, SDS $0,73)$ и длиной тела выше средних значений $(53 \mathrm{~cm}$, SDS 1,99), баллы по шкале Апгар 8/8. После рождения наблюдалась в отделении патологии новорожденных в связи с фетоплацентарной анемией (показатели общего анализа крови в медицинской документации не предоставлены), переломом правой ключицы, синдромом тонусных нарушений. По поводу анемии было проведено переливание эритроцитарной массы на 13-е сутки жизни, получала терапию витаминами группы В, массаж. Выписана на 21-й день жизни в удовлетворительном состоянии.

$\mathrm{Ha}$ 1-м месяце жизни выявлена гипергликемия до 20 ммоль/л без ацетонемии. При обследовании в стационаре по месту жительства установлен диагноз «неонатальный сахарный диабет», назначена инсулинотерапия с хорошим эффектом и положительной динамикой.

В возрасте 6 мес девочка впервые поступила в Институт детской эндокринологии ФГБУ «Национальный медицинский исследовательский центр эндокринологии» (ФГБУ НМИЦ эндокринологии) Минздрава России

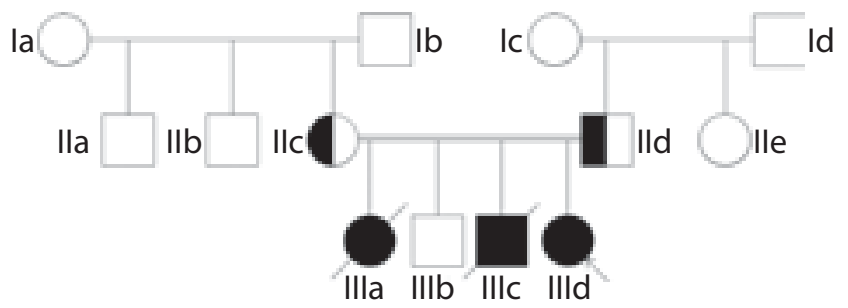

Рис. 2. Генеалогическое древо семьи пробанда. Легенда: Квадраты и круги обозначают мужчин и женщин соответственно. Незакрашенные символы обозначают здоровых людей, которым молекулярно-генетическое исследование гена EIF2AK3 не проводилось. Ilc и IId - здоровые носители гетерозиготной мутации в гене EIF2AK3. IIIa - первый ребенок в семье, погиб в возрасте 3 мес. IIIc - третий ребенок в семье, погиб в 2 года. IIId - пробанд, выявлена гомозиготная мутация в гене EIF2AK3, на настоящее время из компонентов СУР имеется клиника неонатального сахарного диабета. 
в связи с наличием неонатального СД. При объективном осмотре отклонений стигм дизэмбриогенеза не выявлено, росто-весовые показатели (SDS роста 1,2, SDS веса $0,8)$ и психомоторное развитие в норме. По лабораторным данным отмечены повышение гликемии и гликированного гемоглобина (7,9\%), а также гипохромная анемия (гемоглобин 107 г/л, эритроциты 4,1×1012 кл/л) с нормальным уровнем сывороточного железа (19,5 мкмоль/л) и нейтропения $\left(0,75 \times 10^{9}\right.$ кл/л). В биохимическом анализе крови уровень печеночных ферментов (АЛТ 34 Ед/л, АСТ 38 Ед/л) и другие показатели были в пределах референтных значений (общий белок 60 г/л, креатинин 41,6 мкмоль/л, мочевина 4,8 ммоль/л). Аутоантитела к островковым клеткам поджелудочной железы (ICA), глутаматдекарбоксилазе (GAD), тирозинфосфатазе (IA2) и к инсулину (IAA) не обнаружены. Уровни ТTГ (2,0 мME/л) и свободного Т4 (11,6 пмоль/л) в пределах допустимых значений, уровень С-пептида снижен (0,3 нг/мл). Результаты ЭКГ, ЭхоКГ, УЗИ органов брюшной полости и почек без особенностей. Учитывая нестабильные показатели гликемии (3,0-15,0 ммоль/л), различную потребность в дозе инсулина в зависимости от времени суток (0-0,09 Ед/4), девочка была переведена на помповую инсулинотерапию с суточной потребностью инсулина 0,46 Ед/кг/сут с положительным эффектом.

Семейный анамнез отягощен (см. рис. 2): в семье погибли два ребенка. Первый ребенок (IIla на рис. 2) родился в срок с нормальными росто-весовыми показателями, скончался в возрасте 3 мес. Со слов матери, ребенок был здоров, резкое ухудшение состояния произошло в течение суток, отмечались субфебрильная лихорадка, анурия. По результатам патологоанатомического исследования выявлены признаки генерализованной энтеровирусной инфекции, острой почечной недостаточности, гемолитико-уремического синдрома. Второй ребенок в семье (7 лет, IIIb на рис. 2) здоров. Ребенок от третьей, физиологически протекавшей беременности, родился в срок с нормальными параметрами роста и веса (IIIC на рис. 2). У мальчика в возрасте 3 мес. манифестировал ПНСД. В 10 мес проходил обследование в стационаре по месту жительства, выявлена железодефицитная анемия. Ребенок неоднократно переносил инфекции респираторного тракта с гипертермией без существенного ухудшения самочувствия. Также мать отмечала нарушение походки, ротацию правой стопы наружу с 1 года. В возрасте 2 лет, за неделю до ухудшения состояния, мальчик был планово обследован в стационаре по поводу СД, выписан в удовлетворительном состоянии. Затем у ребенка была диагностирована острая респираторная инфекция, к которой через несколько дней присоединилась клиника полиорганной недостаточности. Ребенок погиб в отделении реанимации через 2 мес после манифестации острой респираторной инфекции. В ФГБУ «РДКБ» установлен посмертный диагноз «полиорганная недостаточность, острый гепатит, острая почечная недостаточность, атипичный гемолитико-уремический синдром, вторичная миокардиодистрофия, ангиопатия сетчатки, хроническая инфекция, вызванная вирусом Эпштейна-Барр».

Учитывая кровное родство родителей, отягощенный семейный анамнез, наличие неонатального СД, у пробанда был заподозрен СУР. Ребенку было проведено молекулярно-генетическое исследование (панель
«Моногенные формы сахарного диабета»), по результатам которого была выявлена гомозиготная мутация c.164C>G (p.S55X) в гене EIF2AK3 (МIM\# 604032). У родителей обнаружена идентичная мутация в гетерозиготном состоянии. Молекулярно-генетическое исследование проведено методом высокопроизводительного параллельного секвенирования (платформа Ion Torrent). Использовалась разработанная в отделении наследственных эндокринопатий ФГБУ «НМИЦ эндокринологии» Минздрава России панель праймеров Custom Ampliseq DM_HI, охватывающая кодирующие области следующих генов: GCG, GLUD1, WFS1, HNF1A, GCK, INS, HNF1B, ABCC8, HNF4A, RFX6, PTF1A, NEUROD1, AKT2, ZFP57, INSR, EIF2AK3, PPARG, PAX4, PDX1, GLIS3, KCNJ11, SLC16A1, FOXP3, BLK, CEL, KLF11, SCHAD, GCGR.

В 10 мес девочка поступила в ФГБУ НМИЦ эндокринологии повторно. Через 4 мес после начала помповой инсулинотерапии отмечалась положительная динамика в виде снижения гликированного гемоглобина с 7,9\% до 6,9\%. Однако у ребенка часто возникали гипогликемии в ночное время и после еды, что потребовало коррекции инсулинотерапии. В отделении пациентка перенесла вирусный ринит, наблюдались заложенность носа, слизисто-гнойное отделяемое и гипертермия до $37,7^{\circ} \mathrm{C}$. Общее состояние ребенка оставалось стабильным, самочувствие удовлетворительным, в общем анализе

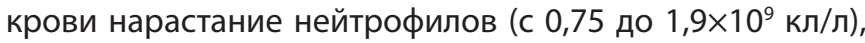
моноцитоз $\left(1,7 \times 10^{9}\right.$ кл/л), анэозинофилия, в биохимических показателях без изменений (АЛТ 16-20 Ед/л, АСТ 45-31 Ед/л, общий белок 61 г/л, креатинин 35,4 мкмоль/л, мочевина 4,1 ммоль/л). Ребенку проводилась симптоматическая терапия жаропонижающими препаратами, местными антисептиками с положительной динамикой. В связи с высоким риском развития острой печеночной недостаточности девочка была консультирована в ФГБУ «ФНЦТИО им. ак. В.И. Шумакова» для решения вопроса о превентивной трансплантации печени от здорового донора. Рекомендовано обследование родителей ребенка для оценки возможности пересадки печени от родственников.

Через 10 дней после выписки из стационара у пациентки повторно развились признаки респираторной инфекции: гипертермия до $39{ }^{\circ} \mathrm{C}$, вялость, гиперемия зева, папулы в области миндалин. В общем анализе крови без значимых изменений (лейкоциты $7,9 \times 10^{9}$ кл/л, нейтрофилы $1,5 \times 10^{9}$ кл/л), сохранялась анемия (гемоглобин 77 г/л). В биохимическом анализе крови на 5-й день заболевания отмечено резкое повышение печеночных ферментов (АЛТ до 4038 Ед/л, АСТ до 3100 Ед/л, лактатдегидрогеназы до 597 Ед/л), умеренное возрастание уровня мочевины (8,6 ммоль/л), другие показатели без значительных изменений (общий белок 58,5 г/л, креатинин 47,4 мкмоль/л). При ультразвуковом исследовании отмечено умеренное увеличение печени. На фоне инфекционного заболевания выраженного колебания показателей гликемии по сравнению с предыдущими наблюдениями не было, субклинические гипогликемии фиксировались до 1 раза в сутки (4,0-5,0 ммоль/л). Получала антибиотикотерапию цефтазидимом, лечение гепатопротекторами и инфузионную терапию. Выписана через 2 нед в удовлетворительном состоянии. 


\section{ОБСУЖДЕНИЕ}

Нонсенс-мутация p.S55X в гене EIF2AK3, выявленная у нашей пациентки, ранее не описана. Тяжелое течение заболевания у пробанда и сибсов в нашем клиническом случае может быть объяснено расположением нонсенс-мутации в первом экзоне, что полностью блокирует синтез PERK. Однако по данным литературы описана гетерогенная клиническая картина у пациентов с СУР даже в случае наличия одинаковой мутации в гене EIF2AK3 у сибсов [9]. Фенотипическая неоднородность заболевания может быть вызвана вариабельностью экспрессии EIF2AK3, наличием других поврежденных генов, эпигенетическими факторами и разницей в протоколах ведения пациентов [5]. Также необходимо учитывать, что в связи с ранней смертностью другие компоненты синдрома у пациентов с СУР в большинстве случаев не успевают манифестировать.

У первого ребенка (Ila на рис. 2) отсутствовали какие-либо проблемы со здоровьем до эпизода острой полиорганной недостаточности. У третьего ребенка (Ilc на рис. 2) был диагностирован ПНСД, отмечались частые инфекционные заболевания верхних дыхательных путей, а также нарушение походки, что может быть проявлением множественной эпифизарной дисплазии (рентгенография костей не проводилась). Принимая во внимание быстрое развитие полиорганной недостаточности на фоне инфекционного заболевания у обоих погибших детей в семье, наличие ПНСД у одного из них, а также обнаружение мутации в гетерозиготном состоянии в гене EIF2AK3 у родителей, высока вероятность наличия СУР у сибсов пробанда.

Обязательным компонентом СУР является СД, который в подавляющем большинстве случаев возникает в возрасте до 6 мес, однако в литературе описано несколько случаев возникновения СД в более позднем периоде: в возрасте 14, 18, 24 мес [10] и даже в 2,5 года [2]. Интересные данные о механизме развития СД при СУР получены благодаря исследованиям, проведенным на мышах с нокаутированным геном Perk. Исследования показали, что основной причиной развития СД является отсутствие экспрессии гена Perk в $\beta$-клетках поджелудочной железы. Также ранее опубликованные данные доказывают, что Perk необходим для пролиферации и дифференцировки $\beta$-клеток. У мышей с нокаутированным геном Perk отмечались выраженный дефицит массы $\beta$-клеток и сниженная секреция инсулина $[11,12]$.

Необходимо помнить, что у некоторых пациентов с СУР возможны гипогликемические состояния, которые связывают с нарушением глюконеогенеза вследствие печеночной недостаточности [4]. Соответствующие данные также получены на мышиных моделях. Более того, эпизоды гипогликемии предшествовали манифестации СД у мышей с нокаутированным геном Perk [11]. Учитывая необходимость аккуратного подбора доз инсулина изза повышенного риска гипогликемии у пациентов с СУР, следует отдавать предпочтение помповой инсулинотерапии $[4,5]$.

Аномалии развития костной системы при СУР весьма вариабельны и могут проявляться множественной эпифизарной дисплазией, остеопорозом, патологическими переломами. У многих пациентов описаны нарушения походки. При этом уровни кальция и фосфора у детей с СУР остаются в пределах нормальных значений [4]. В одной из последних публикаций, посвященных СУР, описан новый компонент заболевания - os odontoideum (несращение зубовидного отростка с телом второго шейного позвонка). Атланто-аксиальная нестабильность может приводить к выраженным неврологическим нарушениям вплоть до параплегии, вынуждая прибегнуть к хирургическому вмешательству [13]. Данная аномалия может быть выявлена при выполнении рентгенографии у пациентов старше 5 лет, в связи с чем нашей пациентке методы визуализации шейного отдела позвоночника не проводились.

Поражение печени также является характерным компонентом СУР. Нередко печеночная недостаточность вместе с СД являются первыми проявлениями СУР. Наиболее часто поражение печени проявляется в виде рецидивирующих эпизодов неинфекционного и неаутоиммунного гепатита, желтухи, гепатомегалии, повышения уровня трансаминаз, острой печеночной недостаточности с высоким риском гипогликемии. Более того, на фоне развития печеночной недостаточности возможно проявление острой почечной и полиорганной недостаточности. Триггерами острой печеночной недостаточности наиболее часто являются инфекционные заболевания [4, 5]. Детям с СУР хирургические вмешательства под общей анестезией рекомендуется проводить в исключительных случаях (по жизненным показаниям), так как наркоз у данной группы пациентов ассоциирован с высоким риском провокации печеночной патологии [4]. Описаны случаи саморазрешения острой печеночной недостаточности, однако данное состояние при тяжелом течении обычно приводит к летальному исходу. Около 50\% детей погибают после первого эпизода острой печеночной недостаточности [5]. После окончания острого периода печеночной недостаточности возможно ухудшение общего состояния пациента с развитием психомоторного отставания и других неврологических осложнений.

Дети с СУР в случае развития острой печеночной недостаточности нуждаются в интенсивном уходе в специализированных учреждениях с возможностью оперативного подключения реанимационной бригады. В настоящее время единственным методом лечения тяжелой печеночной недостаточности у данной группы пациентов является срочная трансплантация печени. В мировой литературе описаны три случая трансплантации печени пациентам с СУР $[2,14,15]$. Двум из них выполнена комбинированная трансплантация печени, почек и поджелудочной железы $[14,15]$. Авторы отмечают, что состояние пациентов непосредственно после операции значительно улучшилось, эпизоды печеночной недостаточности не возобновлялись, а также отпала необходимость в инсулинотерапии.

У ряда пациентов в фазе острой печеночной недостаточности описано развитие вторичного гипотиреоза. После нормализации состояния у некоторых пациентов были повторно изучены уровни ТТГ и свободного Т4: зафиксирован эутиреоз. Предполагается, что центральный гипотиреоз не является компонентом СУР, а лишь отражает общую тяжесть соматического состояния (так называемый синдром эутиреоидной патологии) [9]. 
Таблица 1. Описанные компоненты синдрома Уолкотта-Раллисона.

\section{Поврежденные \\ органы/системы}

Поджелудочная железа

Костная система

- остеопороз
- множественная эпифизарная дисплазия

- os odontoideum

\section{Варианты клинических проявлений}

- неонатальный сахарный диабет

- сахарный диабет с ранним дебютом*

- экзокринная недостаточность поджелудочной железы
- острая рецидивирующая печеночная недостаточность

Печень - рецидивирующее повышение печеночных ферментов без клинических нарушений - хронический гепатит

- гипогликемические состояния

- острая почечная недостаточность

Почки

- хроническая почечная недостаточность

- задержка психомоторного развития

Нервная система

- мозжечковые симптомы

- микроцефалия*

- эпилепсия*

щитовидная железа

- вторичный гипотиреоз

- первичный гипотиреоз*

Кроветворная система

- нейтропения

- анемия

- панцитопения*

- низкорослость

Другие нарушения

- пороки развития сердечно-сосудистой системы*

- гипоплазия легких

- стигмы дисэмбриогенеза*

Примечание: * обозначены симптомы, описанные у одного или у малого количества пациентов

У многих детей с СУР отмечается задержка роста, которая, вероятно, вызвана костными аномалиями, а также может быть усугублена сниженным уровнем инсулиноподобного фактора роста-1 при наличии хронической печеночной недостаточности [16]. Также одними из компонентов СУР являются анемия и нейтропения, которые могут привести к необходимости переливания эритроцитарной массы или использованию колониестимулирующего фактора гранулоцитов соответственно.

Полный список описанных клинических проявлений СУР представлен в табл. 1.

Пациенты с СУР имеют неблагоприятный прогноз и высокую вероятность летального исхода в младенческом возрасте. В литературном обзоре, описывающем 19 пациентов с СУР, 16 детей скончались в возрасте до 10 лет [9]. Основной причиной смерти при СУР является полиорганная недостаточность с преимущественным нарушением функции печени и почек.

Проведение молекулярно-генетического исследования всем детям с неонатальным СД способно помочь в своевременной постановке корректного диагноза. Результаты исследования дают возможность установить причину СД до манифестации других компонентов синдрома [17]. Также молекулярно-генетическое исследование следует рекомендовать в качестве перинатальной диагностики семьям, в которых уже имели место случаи рождения детей с СУР.

Перспективным направлением в лечении СУР является разработка препаратов, способных снизить
«ЭР-стресс» (синтетические шапероны [18], агонисты глюкагоноподобного пептида-1 [19]). Ингибиторы интерферона в экспериментальных исследованиях показали способность снижать отрицательное влияние ингибиторов PERK на ткань поджелудочной железы [20].

\section{ЗАКЛЮЧЕНИЕ}

Синдром Уолкотта-Раллисона следует в первую очередь заподозрить у детей с ПНСД в сочетании с костной дисплазией и/или печеночной недостаточностью, рожденных от близкородственного брака. Проведение молекулярно-генетического исследования всем детям с неонатальным СД способствует своевременной постановке диагноза. Принимая во внимание риск развития гипогликемических состояний, пациентов с СУР, при возможности, следует вести на помповой инсулинотерапии.

Учитывая высокую летальность, тяжесть и мультикомпонентность заболевания, пациенты с СУР должны проходить обследование и лечение в многопрофильных центрах под контролем широкого круга специалистов.

\section{ДОПОЛНИТЕЛЬНАЯ ИНФОРМАЦИЯ}

Источник финансирования. Молекулярно-генетическое исследование было проведено при содействии Фонда поддержки и развития филантропии КАФ. 
Согласие пациента. Родители пациента добровольно подписали информированное согласие на публикацию персональной медицинской информации в обезличенной форме.
Конфликт интересов. Авторы декларируют отсутствие явного и потенциального конфликта интересов, связанного с публикацией настоящей статьи.

\section{СПИСОК ЛИТЕРАТУРЫ | REFERENCES}

1. Wolcott CD, Rallison ML. Infancy-onset diabetes mellitus and multiple epiphyseal dysplasia. J Pediatr. 1972;80(2):292-297. doi: 10.1016/s0022-3476(72)80596-1

2. Rubio-Cabezas O, Patch AM, Minton JA, et al. Wolcott-Rallison syndrome is the most common genetic cause of permanent neonatal diabetes in consanguineous families. J Clin Endocrinol Metab. 2009;94(11):4162-4170. doi: 10.1210/jc.2009-1137

3. Stanik J, Gasperikova D, Paskova M, et al. Prevalence of permanent neonatal diabetes in Slovakia and successful replacement of insulin with sulfonylurea therapy in KCNJ11 and ABCC8 mutation carriers. J Clin Endocrinol Metab. 2007;92(4):1276-1282. doi: 10.1210/jc.2006-2490

4. Julier C, Nicolino M. Wolcott-Rallison syndrome. Orphanet J Rare Dis. 2010;5:29. doi: 10.1186/1750-1172-5-29

5. Habeb AM. Frequency and spectrum of Wolcott-Rallison syndrome in Saudi Arabia: a systematic review. Libyan J Med. 2013;8:21137. doi: 10.3402/ljm.v8i0.21137

6. Deeb A, Habeb A, Kaplan W, et al. Genetic characteristics, clinical spectrum, and incidence of neonatal diabetes in the Emirate of AbuDhabi, United Arab Emirates. Am J Med Genet A. 2016;170(3):602-609. doi: 10.1002/ajmg.a.37419

7. Тихонович ЮВ, Стотикова ОВ, Рубцов ПМ, Тюльпаков АН. Редкая форма неонатального сахарного диабета (НСД), обусловленного дефектом гена EIF2AK3 (синдром Уолкотта-Раллисона) // Проблемы Эндокринологии. - 2015. - Т. 61. —№6. C. 31-35. [Tikhonovich YV, Stotikova OV, Rubtsov PM, Tiulpakov AN. Rare form of Permanent Neonatal Diabetes Mellitus (PNDM) due to novel mutation in EIF2AK3 gene (Wolcott-Rallison syndrome). Problems of Endocrinology 2015;61(6):31-35. (In Russ.)] doi: 10.14341/probl201561631-35

8. Eizirik DL, Cardozo AK, Cnop M. The role for endoplasmic reticulum stress in diabetes mellitus. Endocr Rev. 2008;29(1):42-61. doi: 10.1210/er.2007-0015

9. Ozbek MN, Senee V, Aydemir S, et al. Wolcott-Rallison syndrome due to the same mutation (W522X) in EIF2AK3 in two unrelated families and review of the literature. Pediatr Diabetes. 2010;11(4):279-285. doi: 10.1111/j.1399-5448.2009.00591.x
10. Habeb AM, Deeb A, Johnson M, et al. Liver disease and other comorbidities in Wolcott-Rallison syndrome: different phenotype and variable associations in a large cohort. Horm Res Paediatr. 2015;83(3):190-197. doi: 10.1159/000369804

11. Zhang W, Feng D, Li Y, et al. PERK EIF2AK3 control of pancreatic beta cell differentiation and proliferation is required for postnatal glucose homeostasis. Cell Metab. 2006;4(6):491-497. doi: 10.1016/j.cmet.2006.11.002

12. Feng D, Wei J, Gupta S, et al. Acute ablation of PERK results in ER dysfunctions followed by reduced insulin secretion and cell proliferation. BMC Cell Biol. 2009;10:61. doi: 10.1186/1471-2121-10-61

13. Dias RP, Buchanan CR, Thomas N, et al. Os odontoideum in wolcott-rallison syndrome: a case series of 4 patients. Orphanet J Rare Dis. 2016;11:14. doi: 10.1186/s13023-016-0397-z

14. Rivera E, Gupta S, Chavers B, et al. En bloc multiorgan transplant (liver, pancreas, and kidney) for acute liver and renal failure in a patient with Wolcott-Rallison syndrome. Liver Transpl. 2016;22(3):371-374. doi: 10.1002/It.24402

15. Tzakis AG, Nunnelley MJ, Tekin A, et al. Liver, pancreas and kidney transplantation for the treatment of Wolcott-Rallison syndrome. Am J Transplant. 2015;15(2):565-567. doi: 10.1111/ajt.13005

16. Li Y, lida K, O'Neil J, et al. PERK elF2alpha kinase regulates neonatal growth by controlling the expression of circulating insulin-like growth factor-I derived from the liver. Endocrinology. 2003;144(8):3505-3513. doi: 10.1210/en.2003-0236

17. De Franco E, Flanagan SE, Houghton JAL, et al. The effect of early, comprehensive genomic testing on clinical care in neonatal diabetes: an international cohort study. Lancet. 2015;386(9997):957-963. doi: 10.1016/s0140-6736(15)60098-8

18. Hotamisligil GS. Endoplasmic reticulum stress and the inflammatory basis of metabolic disease. Cell. 2010;140(6):900-917. doi: 10.1016/j.cell.2010.02.034

19. Cunha DA, Ladriere L, Ortis F, et al. Glucagon-like peptide-1 agonists protect pancreatic beta-cells from lipotoxic endoplasmic reticulum stress through upregulation of BiP and JunB. Diabetes. 2009;58(12):2851-2862. doi: 10.2337/db09-0685

20. Yu Q, Zhao B, Gui J, et al. Type I interferons mediate pancreatic toxicities of PERK inhibition. Proc Natl Acad Sci U SA. 2015;112(50):15420-15425. doi: 10.1073/pnas.1516362112

\section{ИНФОРМАЦИЯ ОБ АВТОРАХ [AUTHORS INFO]}

Губаева Диляра Наилевна, аспирант [Diliara N. Gubaeva, MD, PhD student]; адрес: Россия, 117036, Москва, ул. Дм. Ульянова, д. 11 [address: 11 Dm. Ulyanova street, Moscow, 117036 Russian Federation]; ORCID: http://orcid.org/0000-0003- 3922-2869; eLibrary SPIN: 3431-3323; e-mail: gubaevadn@gmail.ru

Лаптев Дмитрий Никитич, К.M.Н., в.н.c. [Dmitry N. Laptev, MD, PhD, leading research associate]; ORCID: http://orcid.org/0000-0002-4316-8546; eLibrary SPIN: 2419-4019; e-mail: laptevdn@ya.ru.

Тюльпаков Анатолий Николаевич, д.м.н., профессор [Anatoly N. Tiulpakov, MD, PhD, Professor]; ORCID 0000-0001-8500-4841; eLibrary SPIN: 8396-1798; e-mail: anatolytiulpakov@gmail.com.

Петрова Лидия Михайловна [Lidia M. Petrova]; ORCID: http://orcid.org/0000-0003-0011-1088; eLibrary SPIN: 8549-7006; e-mail: dob@belodb.ru.

\section{ЦИТИРОВАТЬ:}

Губаева Д.Н., Лаптев Д.Н., Тюльпаков А.Н., Петрова Л.М. Тяжелое течение неонатального сахарного диабета (синдрома Уолкотта-Раллисона), обусловленного нонсенс-мутацией в первом экзоне гена EIF2AK3 // Сахарный диабет. — 2018. - Т. 21. — №1. — C. 42-47. doi: 10.14341/DM8770

\section{TO CITE THIS ARTICLE:}

Gubaeva DN, Laptev DN, Tiulpakov AN, Petrova LM. First trimester thyroid function in pregnant women residing in Saint Petersburg (Russia): reference values and risk of gestational diabetes. Diabetes Mellitus. 2018;21(1):42-47. doi: 10.14341/DM8770 